\title{
Annual Life Cycle and Floral Development of 'Sarah Bernhardt' Peony in Israel
}

\author{
Amalia Barzilay, Hanita Zemah, and Rina Kamenetsky ${ }^{1}$ \\ Department of Ornamental Horticulture, ARO, the Volcani Center, PO Box 6, \\ Bet Dagan 50250, Israel
}

Itzhak Ran
Northern Research and Development, P.O. Box 90 000, Rosh Pina, 12100,
Israel

Additional index words. Paeonia lactiflora, florogenesis, geophyte, SEM

\begin{abstract}
The life cycle and morphogenesis of the floral shoot of Paeonia lactiflora Pallas cv. Sarah Bernhardt were studied under Israeli conditions. The renewal buds for the following year originate on the underground crown, at the base of the annual stems. Bud emergence begins in early spring. Stems elongate rapidly and reach heights of $50-70 \mathrm{~cm}$ in 60-70 days. Flowering begins in April and continues until the end of May. After flowering, the leafy stems remain green until September-October, when the leaves senesce, and the peony plant enters the "rest" stage for 3-4 months. The new monocarpic shoot initiated in the renewal bud at the end of June with the formation of the first leaf primordia and continued to increase in size until February. During summer, the renewal buds remain vegetative. The apical meristem ceases leaf formation after senescence of the aboveground shoots in the fall. During September, the apical meristem of the renewal buds reaches the generative stage and achieves the form of a dome, but remains undifferentiated. In October, floral parts become visible. Floral differentiation is terminated at the beginning of December. Floral initiation and differentiation of peony do not require low temperatures. Morphological development and florogenesis were similar to other geophyte species with an annual thermoperiodic life cycle.
\end{abstract}

Peonies are perennial ornamental plants of the genus Paeonia, which belongs to the family Paeonaceae and consists of 33 species (Rogers, 1996). Species are divided into tree and herbaceous peonies. The latter are commonly grown in the United States, Europe, and Russia as fresh cut flowers and in gardens. Most cultivars are derivatives of $P$. lactiflora Pallas, which originated in China (Kapinos and Dubrov, 1993; Rogers, 1996). One of the most popular cultivars is 'Sarah Bernhardt', with rose double-type flowers, which have a central raised mass of petaloids that are modified stamens and carpels (Rogers, 1996).

Herbaceous peonies are grown successfully in moderate, cold-winter climatic zones, where they bloom in May-July. However, recently, the possibility of flowering them under warmer climatic conditions, e.g., in California and Israel, was reported (Byrne and Halevy, 1986; Halevy et al., 1995). In addition, peonies can be forced under greenhouse conditions (Wilkins and Halevy, 1985; Evans et al., 1990) for early production of cut flowers and potted plants.

Received for publication 7 Nov. 2000. Accepted for publication 6 June 2001

${ }^{1}$ To whom reprint requests should be addressed. Contribution from the Agricultural Research Organization, the Volcani Center, Bet Dagan, Israel, No207/2000 series.
Cultivation of peonies in warmer climates accelerates the flowering process, and provides an excellent early market niche. Hence, the harvest period for commercially grown peonies in California is from late April until early June (Byrne and Halevy, 1986). The first experiments in Israel demonstrated that some cultivars could flower in March-April and even earlier (Halevy et al., 1995; Ran, 2000).

Peonies require low temperatures to break dormancy and promote floral stalk elongation, but the precise information has been collected for only a few cultivars (Byrne and Halevy, 1986). In order to enhance early forcing and profitability of peony, in-depth knowledge of the annual life cycle, floral initiation and differentiation in different climatic conditions is required.

The objectives of this research were to study under Israeli conditions the annual life cycle, the morphogenesis of the monocarpic shoot, and the florogenesis of 'Sarah Bernhardt', one of the most popular and profitable cultivars of peony.

\section{Materials and Methods}

Crowns of 'Sarah Bernhardt' were imported to Israel from a Dutch commercial source in 1996 and were grown in an open plot in the Western Galilee (lat. $35^{\circ} \mathrm{E}$; long. $33^{\circ} \mathrm{N}$ ), a region located in the northwest part of Israel at elevations of 500-700 m above sea level. The climate is characterized by relatively cool winters (temperatures in December-January average 11 to $13^{\circ} \mathrm{C}$, with an average precipitation of $650 \mathrm{~mm}$ ), hot, dry summers (temperatures in July-August average 26 to $27^{\circ} \mathrm{C}$ ), and short and warm springs when air temperatures increase rapidly. Soils in the region are mostly Terra Rossa, a typical red Mediterranean type, with very good structure, high fertility, and a low lime content (Ran, 2000).

Phenological observations on 30 random plants were carried out during the 1997-98 and 1998-99 seasons. The developmental stages, plant height, and size of flower buds were recorded weekly during the seasons of intensive growth until flowering (JanuaryMay) and monthly during the summer and winter (May-January).

Morphogenesis of the monocarpic shoot was studied in 1998-99. Twelve underground buds, each removed from a different plant, were used for each sampling date. The underground buds were of average size for each sampling date and were located at the bases of the annual aboveground stems. The buds were removed from the crowns, and their height from the base to the apical point, as well as their diameter, were measured. The buds were dissected at 2-3 week intervals from June until the end of March, when flowering occurred, and were examined with a stereoscope (Zeiss Stemi 2000-C; Zeiss, Germany) and scanning electron microscope (SEM). For SEM examination, meristems were isolated under a stereomicroscope in petri dishes containing distilled water in order to prevent dehydration. The excised meristems were fixed in a mixture of 5 glacial acetic acid : 5 formalin (40\%) : 90 ethanol $(70 \%)$ and dehydrated in a graded acetone series $(35 \%, 70 \%, 90 \%, 100 \%)$, followed by Freon. Immediately thereafter, tissues were dried using liquid $\mathrm{CO}_{2}$ in a Bio-Rad 750 (Hempstead, England) critical-point dryer. Samples were mounted on SEM stubs with double-stick tape, sputter-coated with a 10-nm layer of gold, and examined with a JSM-35C scanning electron microscope (JEOL, Tokyo) using an accelerating potential of 15-kV (Kamenetsky, 1994).

\section{Results}

General morphology and annual life cycle of the flowering plant. The underground perennial storage organ of peony (crown) develops a large number of perennial roots and monocarpic annual stems. The generative plant of peony is sympodial. The renewal buds are formed on the crown surface at the base of the annual stems and usually produce the flowering stems in the following growing season.

In Israel, bud emergence of 'Sarah Bernhardt' occurs in the early spring (February) (Fig. 1). The leaves unfold in 10-20 d. The stems elongate rapidly and reach a height of $50-70 \mathrm{~cm}$ in $60-70 \mathrm{~d}$. Flowering begins in April and continues until the end of May. The flowers develop at the annual stems from 


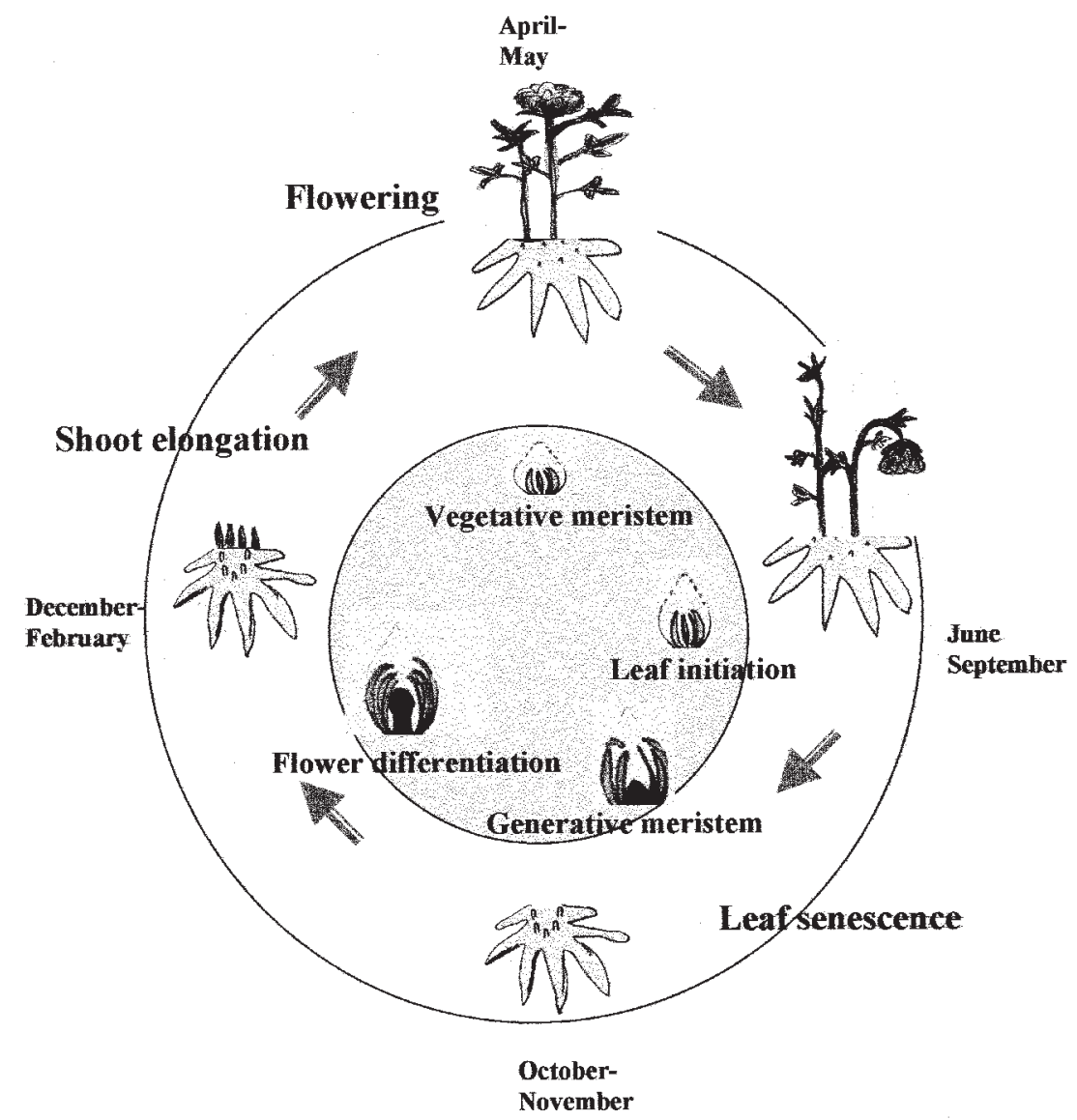

Fig. 1. Life cycle of Paeonia 'Sarah Bernhardt' field-grown in Israel.

terminal and axillary floral buds. Under optimal growing conditions, the terminal flower may reach $15 \mathrm{~cm}$ in diameter, while axillary flowers reach $8-10 \mathrm{~cm}$ in diameter. Each flower consists of five green sepals and numerous petals and petaloids of rose color. After flowering, leafy stems remain green until September-October, when the leaves senesce and abscise, and peony plants enter the "rest" stage, which lasts for 3-4 months.

Morphogenesis of the monocarpic shoot. Renewal buds on the crown are protected by 4-8 specialized cover leaves which firmly envelop the inside parts of the bud. In June, average size of the examined renewal buds was $5.2 \pm 0.6 \mathrm{~mm}$ in height and $4.1 \pm 0.6 \mathrm{~mm}$

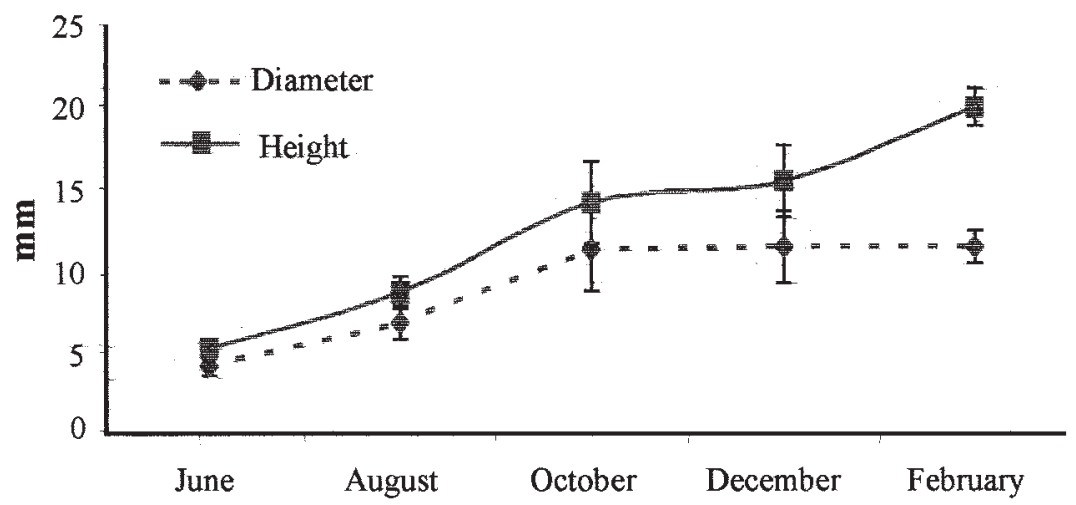

Fig. 2. Growth dynamics of the underground renewal buds of Paeonia 'Sarah Bernhardt' in Israel in JuneFebruary.
At the beginning of September, only 2 out of 12 buds proceeded to the generative stage, but during September apical meristem of all the buds became generative. This alteration was accompanied by visible changes - the apical meristem became round and domeshaped (Fig. 3c). Generative meristems remained undifferentiated and were $0.2 \pm 0.01$ $\mathrm{mm}$ in diameter at the beginning of October. At this time, leaf primordia were $3.6 \pm 0.4$ $\mathrm{mm}$ long in all examined buds. In October, the apical meristems expanded to $0.3 \pm 0.02$ $\mathrm{mm}$ and began to produce sepals, petals, and petaliods (Fig. 3d). Concurrently, the height and diameter of the renewal buds reached $14.1 \pm 2.5$ and $11.2 \pm 2.5 \mathrm{~mm}$, respectively (Fig. 2). At the beginning of November, flower differentiation was observed in $100 \%$ of the renewal buds.

Differentiation of floral parts began on the periphery of the generative meristem and progresses centripetally (Fig. 4b). After formation of numerous petals and petaloids, differentiation ceased at the beginning of December. An undifferentiated space of 0.5$0.7 \mathrm{~mm}$ in diameter remained between central petals of the developing flower (Fig. 4c). However, the differentiation of flower parts was terminated. No formation of the stamens, staminodes, or gynoecium segments was observed. At this stage, the height and diameter of the renewal bud reached $15.4 \pm 2.2$ and $11.4 \pm 2.2 \mathrm{~mm}$, respectively (Fig. 2).

In addition to the central flowering shoot, each renewal bud contains 3-6 axillary shoots (Fig. 4b). In the larger axillary shoots, the apical meristem became generative simultaneously with the central floral bud, and further differentiation of floral parts in the central and axillary buds occurred concurrently. Smaller axillary shoots, however, usually remained vegetative.

Starting at the beginning of December, a fully differentiated monocarpic shoot slowly elongated within the renewal bud. At the beginning of February, just before emergence, the height and diameter of the renewal bud reached $19.9 \pm 1.2$ and $11.4 \pm 1.0 \mathrm{~mm}$, respectively (Fig. 2). It contained central shoot that was $5.0 \pm 0.3 \mathrm{~mm}$ long, and 4-6 axillary shoots, that were 2-4 mm long (Fig. 5).

\section{Discussion}

A morphological analysis of the peony 'Sarah Benhardt' revealed its similarity to other geophyte species with an annual thermoperiodic life cycle. A perennial crown (metamorphosed underground shoot) serves for the accumulation of the storage products (Kapinos and Dubrov, 1993) and plant renewal. Numerous buds, formed on the surface of the crown and near the bases of aboveground stems, develop into monocarpic shoots, which consist of many leaves and terminal and axillary flowers. It was shown by Byrne and Halevy (1986) that, in California, the initiation of flower parts begins in the renewal bud in June. However, in Israel, leaf initiation occurs in the renewal bud in June, after flowering of the parent plants, but the 

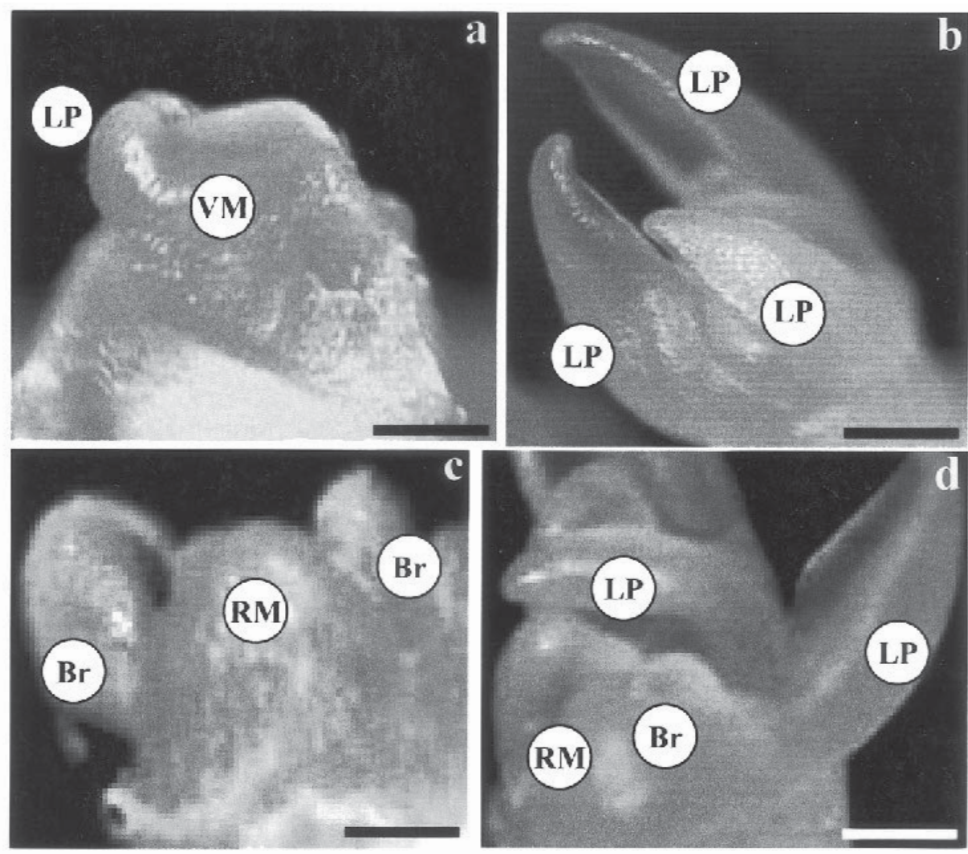

Fig. 3. Stereoscope microphotographs of intrabud development of Paeonia 'Sarah Bernhardt' in Israel. (a) Vegetative meristem (VM) with differentiated leaf primordium (LP). Bar $=0.1 \mathrm{~mm}$. (b) Differentiation of several leaf primordia (LP) in the apical meristem in July. Bar $=0.5 \mathrm{~mm}$. (c) After producing of leaflike bracts $(\mathrm{Br})$, the apical meristem becomes reproductive $(\mathrm{RM})$. Bar $=0.3 \mathrm{~mm}$. (d) Differentiation of bracts $(\mathrm{Br})$ around the generative meristem $(\mathrm{RM})$, leaf primordia $(\mathrm{LP})$ are visible. $\mathrm{Bar}=0.3 \mathrm{~mm}$.

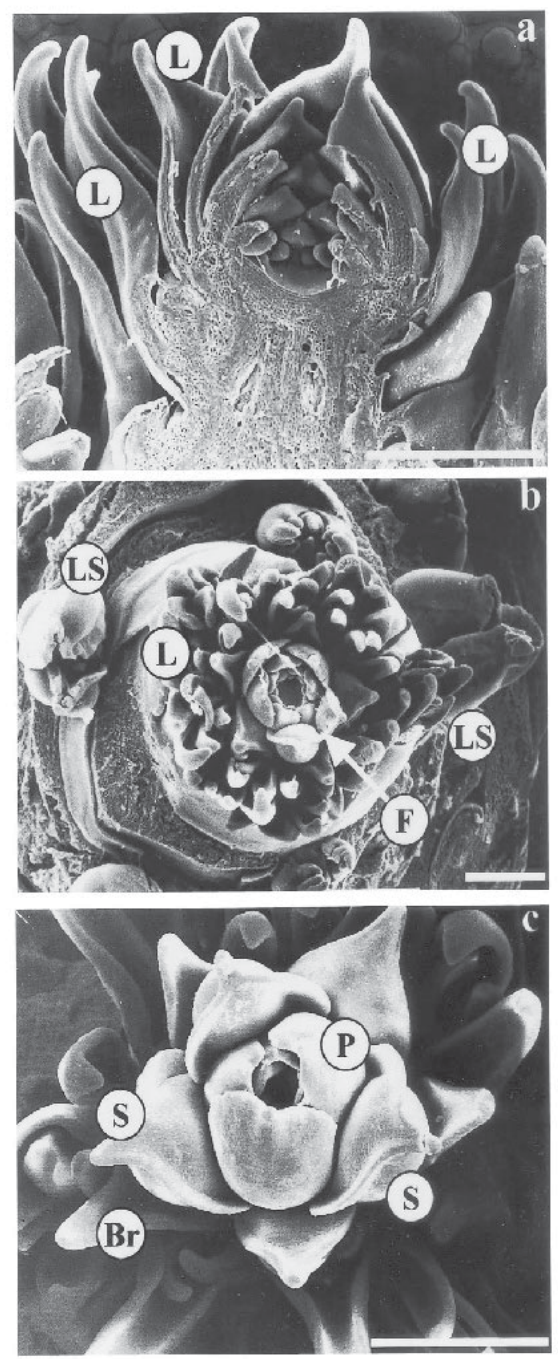

Fig. 4. (left) Scanning electron microphotographs of intrabud development of Paeonia 'Sarah Bernhardt' in Israel. (a) Initiation of leaf primordia $(\mathrm{L})$ in the apical meristem in June. Apical meristem is flat and is visible in the central part of the bud. Bar $=0.5 \mathrm{~mm}$. (b) Floral differentiation in November. Leaf primordia (L) surround the developing flower (F). Petal differentiation begins on the periphery of the generative meristem and progresses centripetally. In addition to the central flowering shoot, each renewal bud contains 3-6 axillary lateral shoots (LS). Cover leaves removed. Bar $=1 \mathrm{~mm}$. (c) After formation of sepals (S), numerous petals $(\mathrm{P})$ and petaloids, differentiation ceases at the beginning of December. An undifferentiated space $0.5-0.7 \mathrm{~mm}$ in diameter remaines between central petals $(\mathrm{P})$ of the developing flower. $\mathrm{Bar}=5 \mathrm{~mm}$.

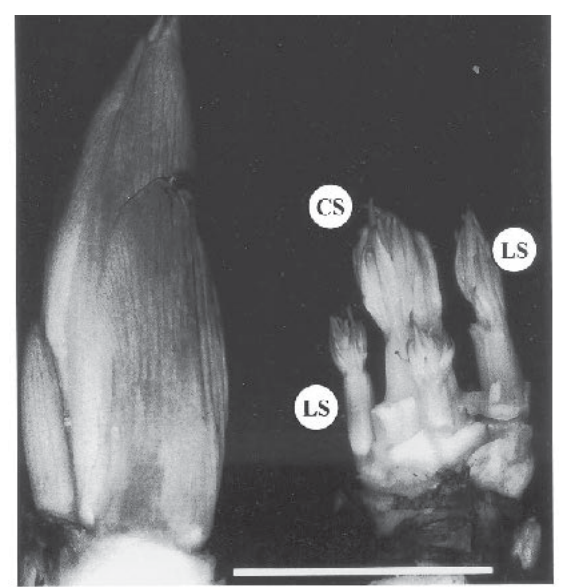

Fig. 5. Structure of the renewal bud of Paeonia 'Sarah Bernhardt' at the beginning of February, just before emergence. The renewal bud is protected by cover leaves (left). It contains central shoot (CS) $0.6-0.7 \mathrm{~cm}$ long, and 4-6 axillary lateral shoots (LS) $0.2-0.5 \mathrm{~cm}$ long. $\mathrm{Bar}=1 \mathrm{~cm}$.

apical meristem remains vegetative until September. The differentiation of floral parts began in October, after senescence of the aboveground shoots, and ceased at the beginning of December.

It is known that flower initiation in geophytes takes place at different times of the year and at different stages in plant development (Le Nard and De Hertogh, 1993a). As in the tulip (Tulipa L.), hyacinth (Hyacinthus orientalis L.), crocus (Crocus L.), and some Allium species (Hartsema, 1961; Kamenetsky, 1997; Le Nard and De Hertogh, 1993b), floral initiation and differentiation of peony does not require cold induction, whereas dormancy break and further elongation of the floral stalk require low temperatures (Byrne and Halevy, 1986). This life cycle differs considerably from those of other geophytes [such as iris (Iris L.), lily (Lilium L.), or onion (Allium cepa L.)], in which cold induction promotes flower initiation (Le Nard and De Hertogh, 1993a; Rabinowitch, 1990).

Since the transition from the vegetative to the reproductive phase occurs in 'Sarah Bernhardt' in September, temperature regime during the summer period may accelerate or delay intrabud florogenesis. This has been shown for other geophytes, e.g., Narcissus (Hanks, 1993), tulip (Le Nard and De Hertogh, 1993b), and Allium (Kamenetsky et al., 2000). Further studies may clarify the effect of high temperatures on flower initiation and contribute to the development of an effective system for peony cultivation in the regions with warm climates.

The flowering of peony, as with many other geophytes, is affected by low temperatures. It has been shown for several peony cultivars that prolonged chilling prior to forcing at warm temperatures promotes dormancy release and flower stem elongation (Byrne and Halevy, 1986; Evans et al., 1990). It is, however, commonly accepted that the developing flower buds become receptive to low temperatures only after they reach a certain stage of development (Le Nard and De Hertogh, 1993a). Thus, the sequence of changes in apical meristem of peony has to be taken into consideration for the development of an effective system for peony forcing, cultivation, or both in warm regions.

\section{Literature Cited}

Byrne, T. and A.H. Halevy. 1986. Forcing herbaceous peonies. J. Amer. Soc. Hort. Sci. 111:379383.

Evans, M.R., N.O. Anderson, and H. F. Wilkins. 1990. Temperature and $\mathrm{GA}_{3}$ effect on emergence and flowering of potted Paeonia lactiflora. HortScience 25:923-924.

Halevy, A.H., D. Weiss, A. Shlomo, V. Naor, M Levy, and M. Cohen. 1995. Introduction of herbaceous peony for cut flower production in Israel. Dapei Meida-Bul. of Israeli Grower's Asn. 5:58-63 (in Hebrew).

Hanks, G.R. 1993. Narcissus, p. 463-558. In: A.A. De Hertogh and M. Le Nard (eds.). The physiology of flower bulbs. Elsevier, Amsterdam.

Hartsema, A.M. 1961. Influence of temperatures on flower formation and flowering of bulbous and 
tuberous plants, p. 123-167. In: W. Ruhland (ed.). Handbuch der Pflanzenphysiologie, Vol. 16. Springer-Verlag, Berlin, Germany.

Kamenetsky, R. 1994. Life cycle, flower initiation and propagation of the desert geophyte Allium rothii. Intl. J. Plant Sci. 155:597-605

Kamenetsky, R. 1997. Inflorescence of Allium species (subgenus Melanocrommyum): Structure and development. Acta Hort 430:141-146.

Kamenetsky, R., Z. Gilad, and E. Rabinowitch. 2000 Development of $A$. aschersonianum from Israeli flora as new ornamental crop for cut flower and bulb production. Final Report, Fdn. of the Chief Scientist of the Ministry of Agr. of Israel, Bet Dagan, 22 p. (In Hebrew, with English summary).

Kapinos, D.B. and V.M. Dubrov. 1993. Peonies in the garden. Minion, Tumen, Russia (in Russian).

Le Nard, M. and A.A. De Hertogh. 1993a. Bulb growing and development and flowering, $\mathrm{p}$. 29-44. In: A.A. De Hertogh and M. Le Nard (eds.) The physiology of flower bulbs. Elsevier, Amsterdam.

Le Nard, M. and A.A. De Hertogh. 1993b. Tulipa p. 617-682. In: A.A. De Hertogh and M. Le
Nard (eds.). The physiology of flower bulbs. Elsevier, Amsterdam.

Rabinowitch, H.D. 1990. Physiology of flowering, p. 113-134. In: H.D. Rabinowitch and J.L. Brewster (eds.). Onions and allied crops. I. Botany, physiology, and genetics. CRC Press, Boca Raton, Fla.

Ran, I. 2000. Commercial growing herbaceous peonies in Israel. Amer. Peony Soc. Bul. 31:26-30. Rogers, A. 1996. Peonies. Timber Press.

Wilkins, H.F. and A.A. Halevy. 1985. Paeonia, p. 2-4. In: A.H. Halevy (ed.). Handbook of flowering, Vol. IV. CRC Press, Boca Raton, Fla. 